\title{
Synthesis, mechanical and thermal properties of carbon black/epoxy composites
}

\author{
Tanusree Bera $^{1}$, S.K. Acharya ${ }^{1}$, Punyapriya Mishra ${ }^{2}$ \\ ${ }^{1 *}$ Department of Mechanical Engineering, National Institute of Technology, Rourkela, INDIA \\ ${ }^{2}$ Department of Mechanical Engineering, Veer Surendra Sai University of Technology, Burla, INDIA \\ *Corresponding Author: e-mail: tanusree.bera@gmail.com, Tel +91-9778574700
}

\begin{abstract}
In the present work, epoxy/carbon black (CB) composites were made with 1, 2, 3, 4 and 5 wt. \% of CB. The tensile test, flexural test, and impact test of the epoxy/CB composites and neat epoxy were performed and, their results were compared. The results conclude that the tensile strength, flexural strength, and impact strength of the 4 wt. \% of CB composites is better than the other composites and neat epoxy. Thermal graphic analysis (TGA) and differential scanning calorimeter (DSC) of the pure epoxy and composites were calculated and analyzed. The results found that the glass transition (Tg) of the neat epoxy was increased with the addition of CB content up to 4 wt. \% and then it was decreased. The decomposition temperature of the composites was increased with the increased in the $\mathrm{CB}$ content.
\end{abstract}

Keywords: Carbon black (CB), Epoxy, composites, TGA, DSC, Glass transition temperature (Tg)

DOI: http://dx.doi.org/10.4314/ijest.v10i4.2

\section{Introduction}

From the last many decades, polymer materials have found great applications in the various industries. The utilization of polymer materials in everyday life of human beings has placed an important role. The applications of polymers are steadily increasing due to its low density and cost compared to metals and ceramics. However, the polymer in its pure form unable to satisfy the demands in various fields, where a combination of good mechanical and thermal properties is required. Hence reinforcements are needed to provide additional strength for polymers. The choice of the reinforcement for the polymer matrix is very important; the reinforcement should be such that which can reduce the manufacturing cost of the polymer matrix composites PMCs, tailors the properties of the same and many more.

$\mathrm{CB}$ is a material obtained from the incomplete combustion of petroleum products. It has a high surface-area-to-volume ratio (https://en.wikipedia.org/wiki/Carbon_black). The majority of the CB finds its use as reinforcement in vulcanized rubber goods, coating, plastics, ink, and inkjet applications (Li et al., 2005; Jakab and Omastova, 2005). It is found from the literature that CB is extensively used as a filler material in the polymer industry due to its qualities and characteristics (Zhang et al., 2008).

Extensive studies have been carried out by various researchers for the synthesis and characterization of CB as reinforcement in a polymer matrix to fabricate $\mathrm{CB}$ a polymer composite. During the vulcanization of rubber, $\mathrm{CB}$ is used as the filler, because incorporation of carbon black into the rubber matrix enhances the mechanical, wear resistance and reduced the manufacturing cost of the rubber product (Okieimen and Iman, 2003). Imoisil et al., 2013 worked on the mechanical properties of natural rubber reinforced with rice-husk/carbon black hybrid filler composite. The results revealed that tensile strength, compression strength, abrasion resistance and hardness properties of the natural rubber improves with an increase in CB content, whereas fracture strain decreases with increase in the addition of carbon black. Khalil et al., 2010 produced CB/epoxy composites; the CB is obtained from pyrolysis of bamboo stem, coconut shell, and oil palm empty fiber bunch at $700{ }^{\circ} \mathrm{C}$. The results showed that the composites exhibited better flexural properties and thermal stability compared to the neat epoxy resin. Tantawy et al., 2002 developed epoxy resin-carbon black composites and concluded that the composites exhibited good electrical and thermal stability. Kuzhir et al., 
2013 investigated epoxy composites with various fillers; CB, carbon nanotubes (CNTs) and micro-sized exfoliated graphite (EG). The authors revealed that the CB composites are electromagnetically, mechanically, thermally stable than the expensive CNTs and EG composites. Yuen et al., 2007 developed multi-walled carbon nanotube (MWCNT)/epoxy composites. The authors concluded that the glass transition temperature (Tg) of MWCNT/epoxy composites increased with $0.5 \mathrm{wt}$ \% MWCNT. The surface resistivity and bulk resistivity of the composites are decreased. The dielectric constant is increased. Zhou et al., 2010 produced epoxy composites using hybrid MWCNTs/micro-SiC fiber. Authors observed that the thermal conductivity increased by the addition of 6 wt. \% MWCNTs or $71.7 \mathrm{wt}$ \% micro-SiC to an epoxy resin. Guadagno et al., 2009 observed that the epoxy/MWCNTs composites showed a higher elastic modulus and improved barrier properties. Inam et al., 2013 worked on mechanical properties of epoxy resin with carbon nanotube lengths. It has been observed by the authors that the nano-composites having long carbon nanotubes possess higher tensile strength, elastic modulus, fracture strain and fracture toughness as compared to nano-composites containing short carbon nanotubes.

Rahmani et al., 2014 developed epoxy/carbon fiber laminated composites and concluded that the mechanical properties of composites made with five-ply are greater than the three-ply composites. Wen et al., 2017 worked on Epoxy/Carbon fiber and Bamboo charcoal and Epoxy/CB with Bamboo charcoal. The results revealed that the Bamboo charcoal/CB and bamboo charcoal/carbon fiber composites have good conductive network structure and better dynamic thermal, mechanical properties. Leemsuthep et al., 2017 found that the sodium bicarbonate exhibited a significant effect on the morphology, thermal and conductivity properties of carbon black-filled epoxy porous (CBEP). Yue et al., 2017 investigated on the Epoxy-CB composites foams and found that the foaming improves the electrical conductivity and mechanical properties. Phua et al., 2017 worked on the influence of thermoplastic spacer on the mechanical, electrical, and thermal properties of CB/epoxy composites. The results concluded that at 10 vol. \% polymethylmethacrylate (PMMA) spacer, the filled system shows promising improvement in electrical conductivity, thermal and mechanical properties with three orders of magnitude increment at 15 vol. \% CB loading.

It is found from the above literature survey that there are lots of work on the expensive CNTs, and MWCNTs, but still a lot more work has to be done on the inexpensive CB. Here in this present study, an attempt has been made to make epoxy/CB composites and studied the mechanical and thermal properties.

\section{Experimental studies}

The epoxy resins used in the present work is the diglycidyl ether of bisphenol A (DGEBA) a liquid epoxy resin which represents greater than $75 \%$ of the resin used in industrial applications. It is available under trade name Araldite ${ }^{\circledR}$ GY 257 which is the registered trademark for Huntsman Advanced Materials' commercial resins. This Epoxy Resin is supplied by M/S-Singhania Suppliers, Kolkata. It is a low viscosity crystallization-resistant epoxy resin based on bisphenol A and modified with a reactive diluent. In the present work the curing agent/hardener used was A-140. "Aradur®." - 140 is the trademark of Huntsman Advanced Materials' limited for commercial hardeners. The CB is used as filler in the study. It is procured from Cabot Corp., Billerica, MA having product name of VULCAN® XC72. It is in powder form with a size of $30 \mathrm{~nm}$ and a density of $1.8 \mathrm{~g} / \mathrm{cm}^{3}$.

Epoxy resin and CB is heated separately inside a vacuum oven for $1 \mathrm{hr}$ at $60^{\circ} \mathrm{C}[ \pm 20 \mathrm{C}]$. Mixing of resin with $\mathrm{CB}$ is carried out by H.S.M (high-intensity mechanical liquid stirrer) at approximately $500 \mathrm{rpm}$ speed and $60^{\circ} \mathrm{C}[ \pm 20 \mathrm{C}]$ for $1 \mathrm{hr}$. The curing agent is added to the mixture at predetermined parts per hundred ratios. The solution is gently mixed for 15-20 minutes to avoid introduction of any air bubbles due to mixing action. The final slurry, free from air bubbles, is poured into a preheated brass mould $(165 \times 165 \times 3 \mathrm{~mm})$ at $80^{\circ} \mathrm{C}[ \pm 20 \mathrm{C}]$ and cured in the vacuum oven at $-760 \mathrm{~mm}$ of $\mathrm{Hg}$ for $1 \mathrm{hr}$. Post curing is carried out in two phases: First at $120^{\circ} \mathrm{C}[ \pm 20 \mathrm{C}]$ for $2 \mathrm{hrs}$ inside a vacuum oven and then at room temperature for $48 \mathrm{hrs}$. The above procedure will be repeated for different wt. \% (0-7\%) of CB to get the sheets of composites.

Tensile tests are conducted on a computerized Universal Testing Machine (UTM; H10KS, Hounsfield Test Equipment Ltd, England) according to the ASTM D 3039-76 standard specimens with $165 \mathrm{~mm} \mathrm{X} 165 \mathrm{~mm} \mathrm{X} 3 \mathrm{~mm}$ dimensions of the specimen at $1 \mathrm{~mm} / \mathrm{min}$ cross-head rate with $10 \mathrm{KN}$ load cell. The Flexural test is performed on a 3-point bend test method according to ASTM D790-03 standard method using the same UTM used for the tensile test. The impact test of the composite is carried on Charpy impact tester (Veekay Test lab, Mumbai, Maharashtra, India). The tests are done as per ASTM. The Charpy test involves striking a suitable test piece with a striker, mounted at the end of a pendulum. The specimen was fixed in place at both ends, and the striker impacts the specimen immediately behind a machined notch. The Calorimetric study is observed on differential scanning calorimeter (DSC). Samples are having a weight of $10 \mathrm{mg}$ each is prepared by a homogeneous mixture of epoxy resin and carbon black filler. It is performed at $20-300{ }^{\circ} \mathrm{C}$ temperature with a rate of $2{ }^{\circ} \mathrm{C} / \mathrm{min}$. Thermo Gravimetric analysis (TGA) of epoxy/carbon black composites is performed on the Perkin-Elmer 7 with TAC -instrument controller. The objective of TGA is to measure the change in mass of a sample, as the sample is heated. The samples are heated under dry nitrogen gas at a heating rate of $10^{\circ} \mathrm{C} / \mathrm{min}$ from room temperature up to $525^{\circ} \mathrm{C}$.

\section{Results}

3.1 Effect of CB on Tensile strength: The Tensile strength of a neat epoxy and epoxy/CB composites is shown in Figure 1. It is observed from Figure 1 that the tensile strength of the unreinforced and reinforced composites increased with the addition of CB. 
The increase in the CB content, the tensile strength increased (Imoisili et al., 2013). The tensile strength of the neat epoxy increased from $39 \pm 2.2 \mathrm{MPa}$ to $58 \pm 2.6 \mathrm{MPa}$ with $4 \mathrm{wt}$. \% of CB loading. This is because carbon is a good reinforcing element (Okieimen and Imanah, 2003). However, further addition of CB after $4 \%$; the strength of the composites decreases because CB platelets would not intercalate or exfoliate in the epoxy resin. During dispersion of CB particles in the epoxy matrix, the viscosity of the resin system increase and that prevent the easy movement of CB particles and leads uneven distribution of CB particles in the matrix. Otherwise, this may be due to weak chemical reaction at the interface of the epoxy and CB which reduces the transfer of tensile stress from the matrix to the filler. Figure 2 shows the tensile modulus graph. The tensile strength and tensile modulus are almost having similar graphs.

3.2 Effect of CB on Flexural strength: The flexural strength of the neat epoxy and epoxy/CB composites is shown in Figure 3 . The flexural strength values exhibit similar behavior as seen in the tensile strength. The strength increases steadily up to 4 wt. \% of CB loading after that it decreases. This can be attributed to the incompatibility between the epoxy resin and CB particles. Figure 4 shows the flexural modulus with various CB content. It is observed from Figure 4 that the flexural modulus increases gradually up to $4 \mathrm{wt}$. \% of CB after that it again gradually decreases. This observation is similar to previous work by other authors. Etika et al., 2009 evaluate the influence of carbon black on mechanical properties of epoxy composites using dynamic mechanical analysis. It was found that storage moduli of the epoxy composites at $25^{\circ} \mathrm{C}$ increased on addition of CB. Composites with $2.5 \mathrm{wt} \% \%$ and $5 \mathrm{wt}$. $\%$ CB show 19\% and 23\% higher modulus than neat epoxy, respectively. Good interfacial bonding between carbon black fillers and epoxy matrix has been shown to transmit stress from the matrix to the filler, and further promotes the enhancement of flexural property of epoxy composites (Yang et al., 2009; Nayak et al., 2007; Khalil et al., 2010).

3.3 Effect of $C B$ on Impact strength: It is observed from Figure 5 that the impact strength of the epoxy/CB composites showed an increasing trend with an increase in CB content up to $4 \%$. At this CB content, a minimum of $60 \%$ increase in impact energy is obtained. The neat epoxy resin has the maximum impact strength $1.5 \mathrm{~kJ} / \mathrm{m}^{2}$ and composite at $4 \mathrm{wt} . \%$ composite has the maximum impact strength of $2.7 \mathrm{~kJ} / \mathrm{m}^{2}$. However, strength decreases after $4 \mathrm{wt}$. \% of the reinforced composite. Higher impact strength indicates the capability of the composite to absorb energy.

3.4 Differential scanning calorimeter (DSC): The glass transition temperatures (Tg) of neat epoxy and epoxy/CB composites are determined by differential scanning calorimeter (DSC). Figure 6 shows the effects of the CB on the Tg of the developed composites. DSC analyses indicated that Tg of the cured composites increased continuously with CB loading. It is observed from Table 1 that the neat epoxy has $\mathrm{Tg}$ of $68{ }^{\circ} \mathrm{C}$, addition of $4 \mathrm{wt} . \% \mathrm{CB}$ into the epoxy resin increased $\mathrm{Tg}$ to $90{ }^{\circ} \mathrm{C}$. The same type of trend is obtained by Yuen, et al., 2007. The increase in the Tg with CB addition may be attributed to consumption of un-reacted monomers on the surface of the CB particles. Hence, crosslink density increases by increasing CB loading on the pure epoxy (Remiro et al., 2002). Finally, the increase in the crosslink density may result in higher Tg. Beyond 4 wt. \% of filler loading Tg value decreased, this can be due to consumption of un-reacted monomers in the galleries and entanglements. This observation is similar to previous work by other authors (Gojny et al., 2004; Sun et al., 2004; Khalil et al., 2010).

3.5 Thermo Gravimetric Analysis (TGA): Thermo Graphics Analysis (TGA) of epoxy/CB composites is presented in Figure 7. The initial decomposition temperature of pure epoxy is increased in the order of $5-10{ }^{\circ} \mathrm{C}$ with $\mathrm{CB}$ loading. Degradation resistance of pure epoxy is slightly improved by the addition of the carbon black up to $4 \mathrm{wt}$. $\%$ as shown in Table 2 . The initial decomposition temperature of the neat epoxy increased from $302{ }^{\circ} \mathrm{C}$ to $310{ }^{\circ} \mathrm{C}$ with $4 \mathrm{wt} . \% \mathrm{CB}$ loading. This is attributed to the barrier properties, as the reinforcing particles behave as an insulator, which results in a reduction of the heat transfer within the composites (Remiro et al., 2002). The Initial decomposition temperature and the weight remaining after decomposition are shown in Table 1. After the decomposition of the epoxy/CB composites, char formation takes place. Neat epoxy has char formation of $4.94 \%$ and, char formation is $11.68 \%$ for composites with $4 \mathrm{wt}$. \% CB content. The amount of char formation increases continuously with $\mathrm{CB}$ loading. The weight losses of CB loading in Epoxy resin can be divided into three parts: 1st minor weight loss region in the temperature range from $50{ }^{\circ} \mathrm{C}$ to $250{ }^{\circ} \mathrm{C}$; 2nd major weight loss region in the temperature range from $250{ }^{\circ} \mathrm{C}$ to $475{ }^{\circ} \mathrm{C}$; and 3 rd post major weight loss region in the temperature range from $475{ }^{\circ} \mathrm{C}$ to $800{ }^{\circ} \mathrm{C}$. The 1 st minor weight loss region can most probably be attributed to evolution of moisture and volatile elements. 2nd major weight loss region can evidently be attributed to degradation of epoxy matrix itself. 3rd weight loss region is attributed to thermo-oxidation of the remaining degradation products of the epoxy resin. In general as a result of CB addition, TGA curves are shifted to higher temperature. Similar results have been reported in other works (Bai and Allaoui, 2003; Kuzhir et al., 2013).

3.6 SEM observation: From the SEM images, as shown in Figure 8, the CB is shown as micro-ribbon with about several microns in length and about $200 \mathrm{~nm}$ in width. It is not hard to imagine when this kind of micro-ribbon is evenly distributed across the matrix; it would inter-lock and entangle with the polymer chains in the matrix. For the ease of comparison, except the SEM image of CB, the SEM images of 0 wt. \%, 2-4 wt. \% each of CB, epoxy samples are all focused to a magnification of 10,000. For the 2-4 wt. \% CB/epoxy composites as shown in the SEM image in Figure $8(\mathrm{~b}-\mathrm{d})$, the cleavage surface is a big different from that of the 
pure epoxy sample in Figure 8 (a). The cleavage surface showed fracture pieces with smooth white facture borders. Tiny white lines, which believed to be the CB, are found coming out from the fracture surfaces. Therefore, the CB introduced inside the epoxy acted like the grid lines of a net. The micro-ribbon would interlock with the epoxy network chains. With the addition of higher $\mathrm{CB}$ content, the interlocking mechanism seemed to prevail more comprehensively. Therefore, it seemed that an increase in the proportion of CB increases the stiffness of the composite (Rosszainily et al., 2016).

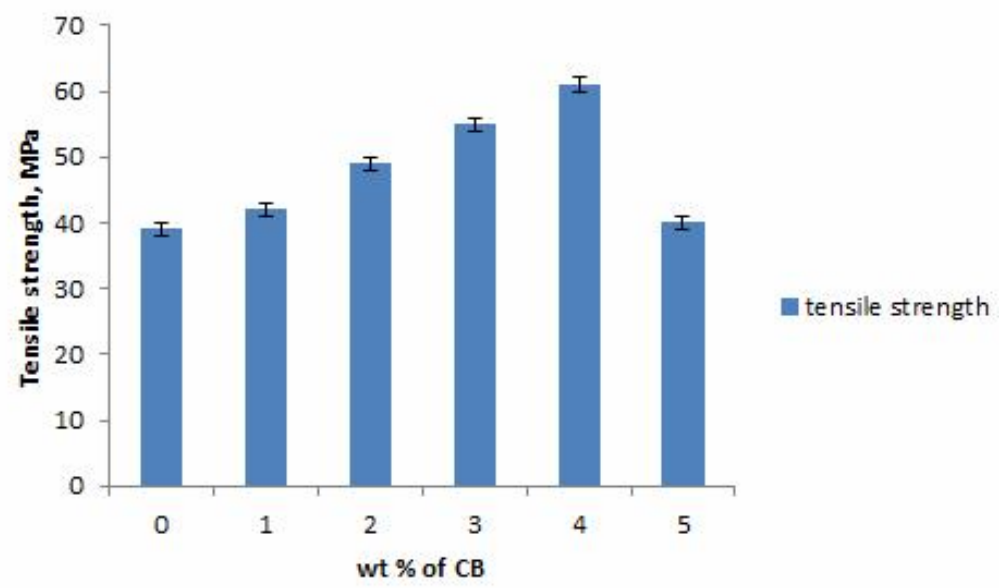

Figure 1. Tensile strength of CB-Epoxy composites for different weight percentage of CB

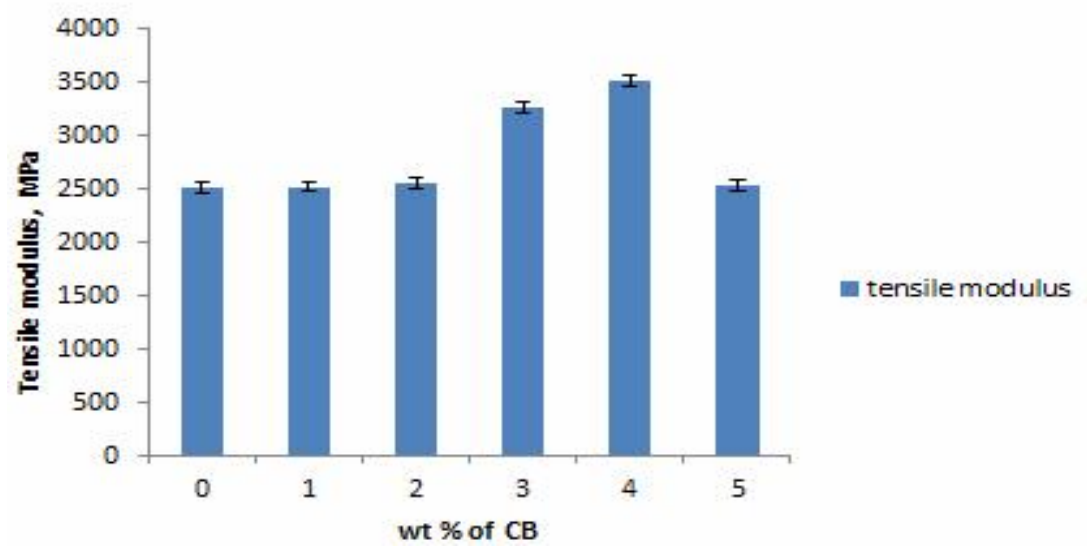

Figure 2. Tensile modulus of CB-Epoxy composites for different weight percentage of CB

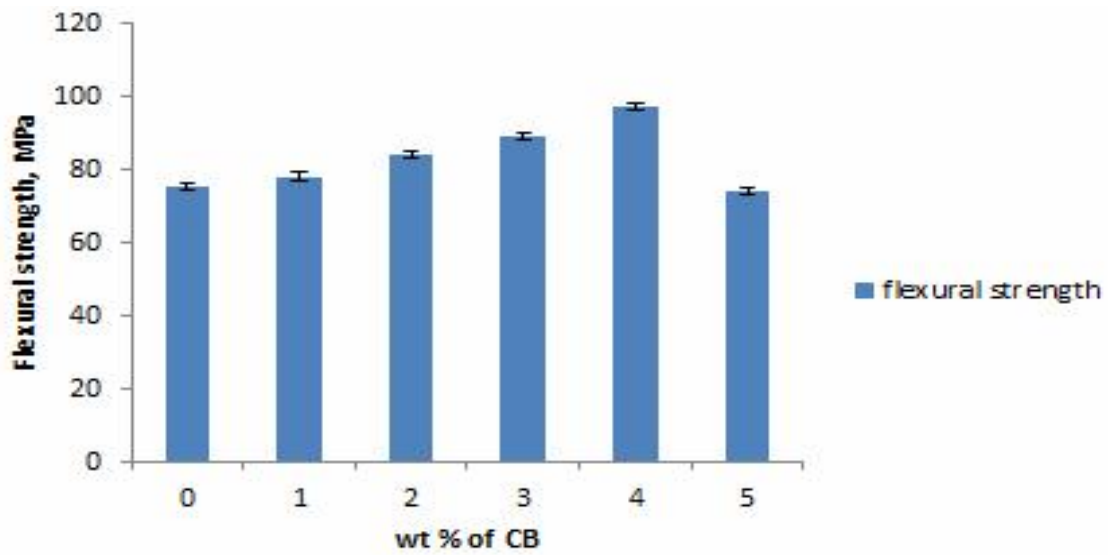

Figure 3. Flexural strength of CB-Epoxy composites for different weight percentage of CB 


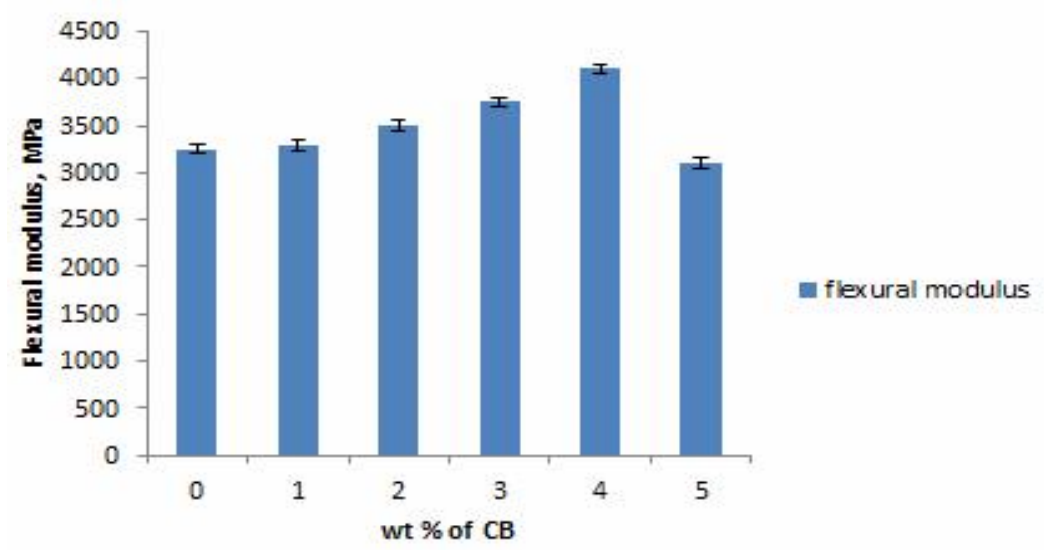

Figure 4. Flexural modulus of CB-Epoxy composites for different weight percentage of CB

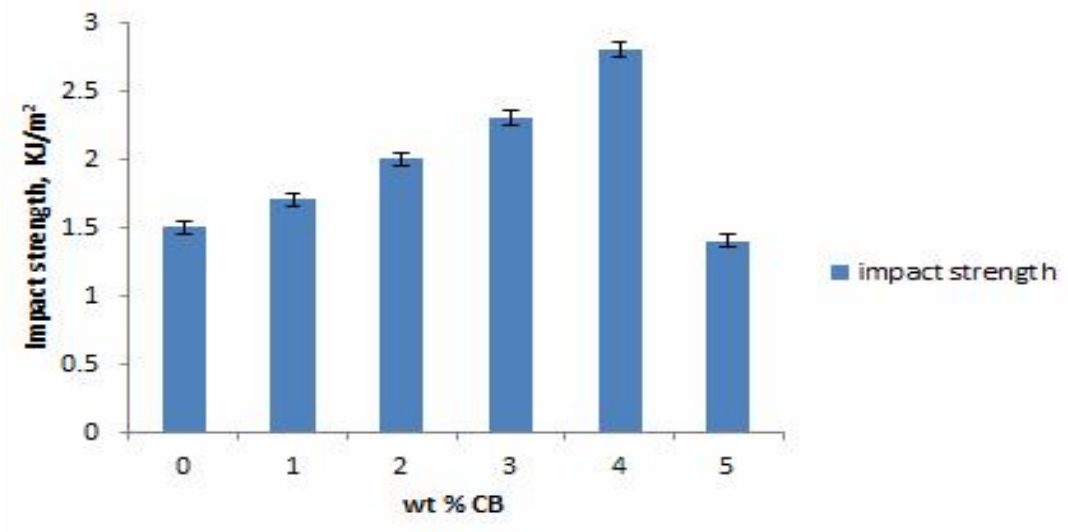

Figure 5. Impact strength of CB-Epoxy composites for different weight percentage of CB

Table 1. Glass transition temperature $\left(\mathrm{T}_{\mathrm{g}}\right)$, decomposition temperature and weight remaining after decomposition of epoxy carbon black composites

\begin{tabular}{|c|c|c|c|}
\hline Composite Samples & $\operatorname{Tg}\left({ }^{\circ} \mathrm{C}\right)$ & $\begin{array}{c}\text { Initial Decomposition } \\
\text { temperature }\left({ }^{\circ} \mathrm{C}\right)\end{array}$ & Weight remaining (\%) \\
\hline Neat Epoxy & 68.70 & 302 & 4.94 \\
\hline Epoxy + 2 wt. \% CB & 70.04 & 308 & 8.63 \\
\hline Epoxy + 3 wt. \% CB & 87.89 & 309 & 8.57 \\
\hline Epoxy + 4 wt. \% CB & 90.23 & 310 & 11.68 \\
\hline
\end{tabular}

Table 2. Thermo gravimetric analysis of epoxy carbon black composites

\begin{tabular}{|c|c|c|c|c|c|c|c|c|}
\hline S1. No & Sample & $\mathrm{T}_{\text {onset }}$ & $\mathrm{T}_{\text {end }}$ & $\mathrm{T}_{\text {peak }}$ & $\mathrm{T}_{10 \%}$ & $\mathrm{~T}_{30 \%}$ & $\mathrm{~T}_{50 \%}$ & $\mathrm{~T}_{100 \%}$ \\
\hline 1 & Neat Epoxy & 302.67 & 402.44 & 364.04 & 361.75 & 388.93 & 402.57 & 600 \\
\hline 2 & 2 wt. \% CB & 308.50 & 409.75 & 366.12 & 362.94 & 390.84 & 414.90 & 610 \\
\hline 3 & 3 wt. \% CB & 309.25 & 410.63 & 365.11 & 357.20 & 387.65 & 460.47 & 478.30 \\
\hline 4 & 4 wt. \% CB & 304.64 & 406.81 & 364.64 & 364 & 389.17 & 466.83 & 481.34 \\
\hline
\end{tabular}




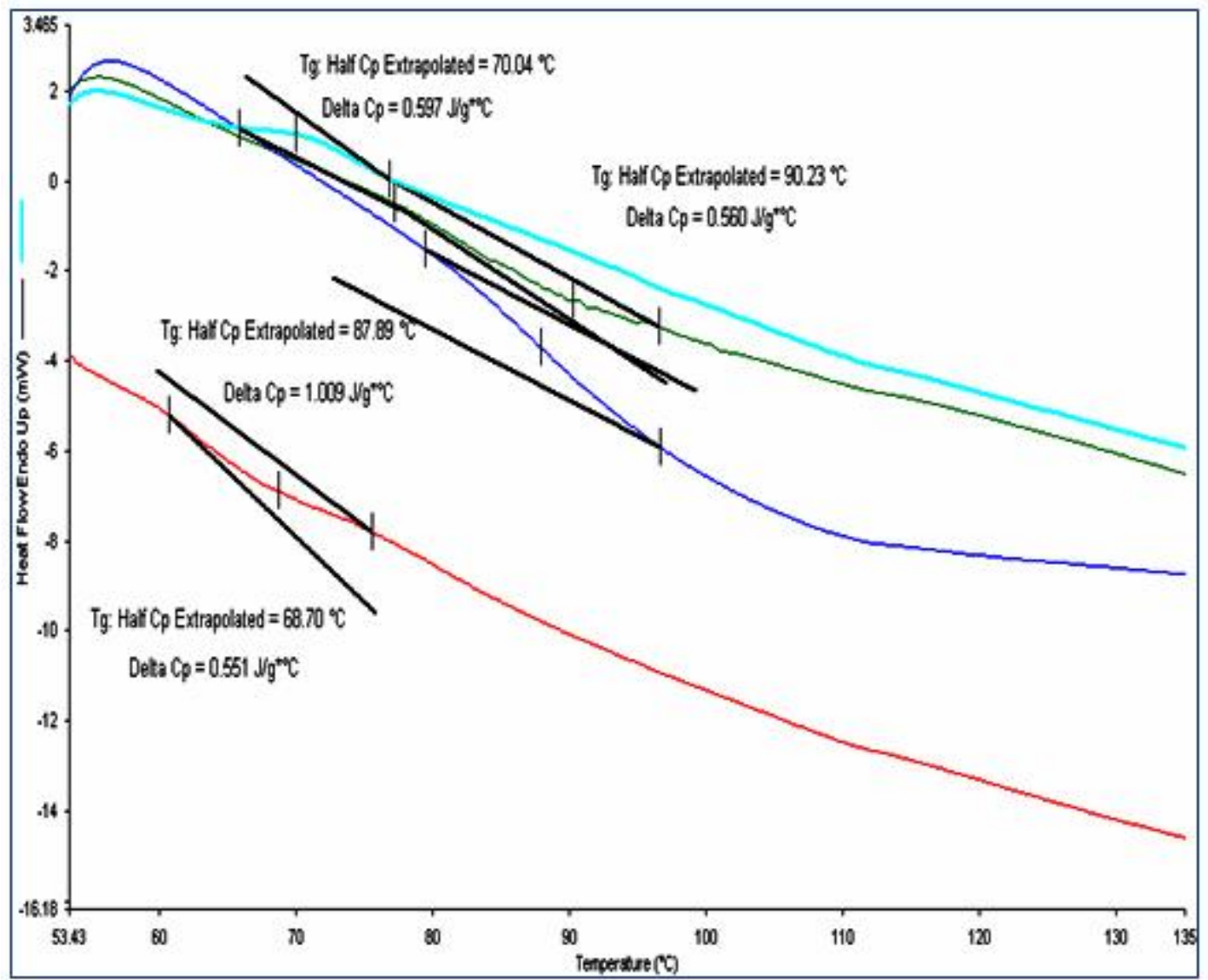

Figure 6. DSC Thermogram of CB-Epoxy composites for different weight $\%$ of CB

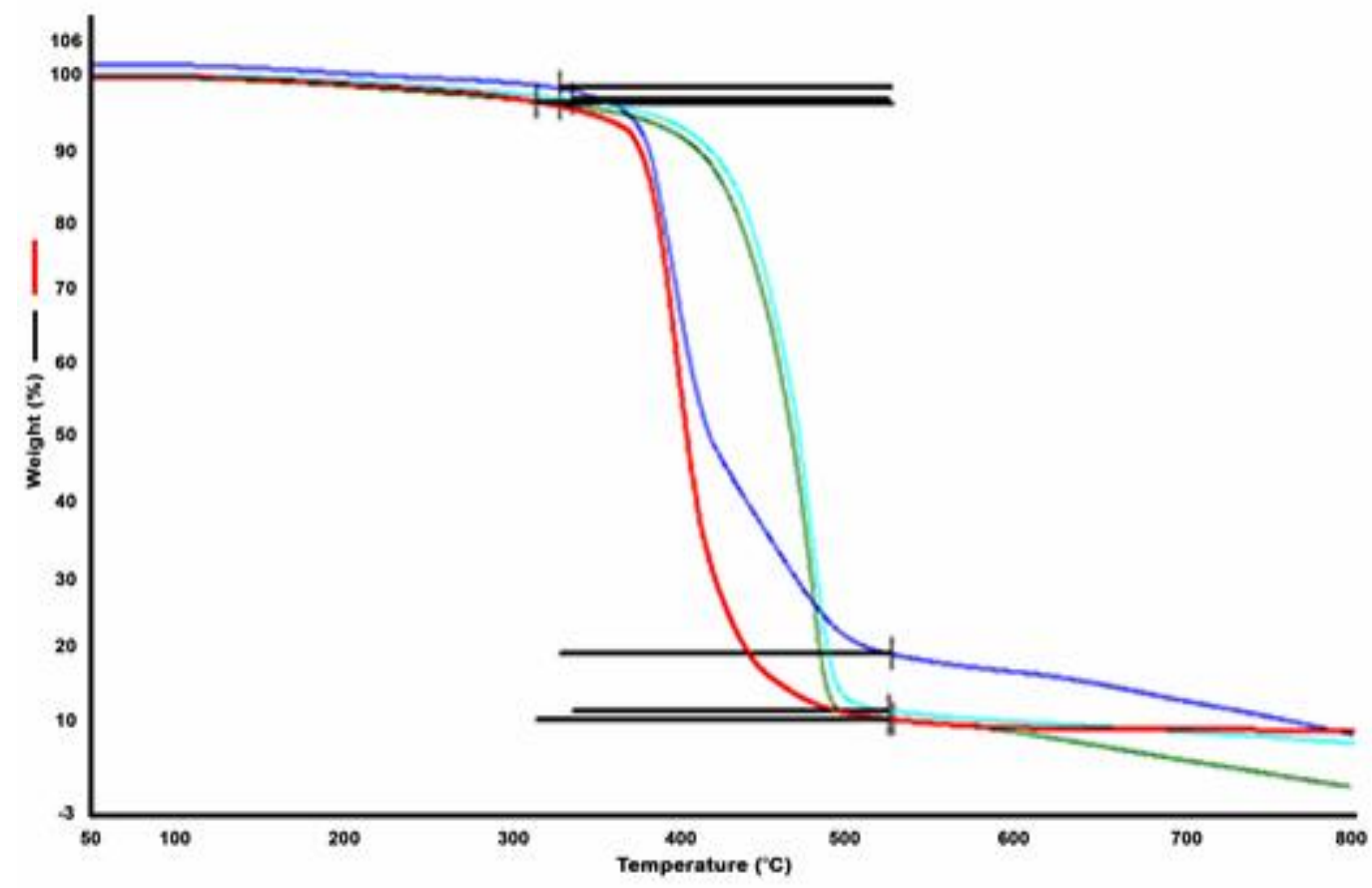

Figure 7. Percentage weight loss of the $\mathrm{CB}$ /epoxy composites due to heating in presence of $\mathrm{N}_{2}$ atmosphere 

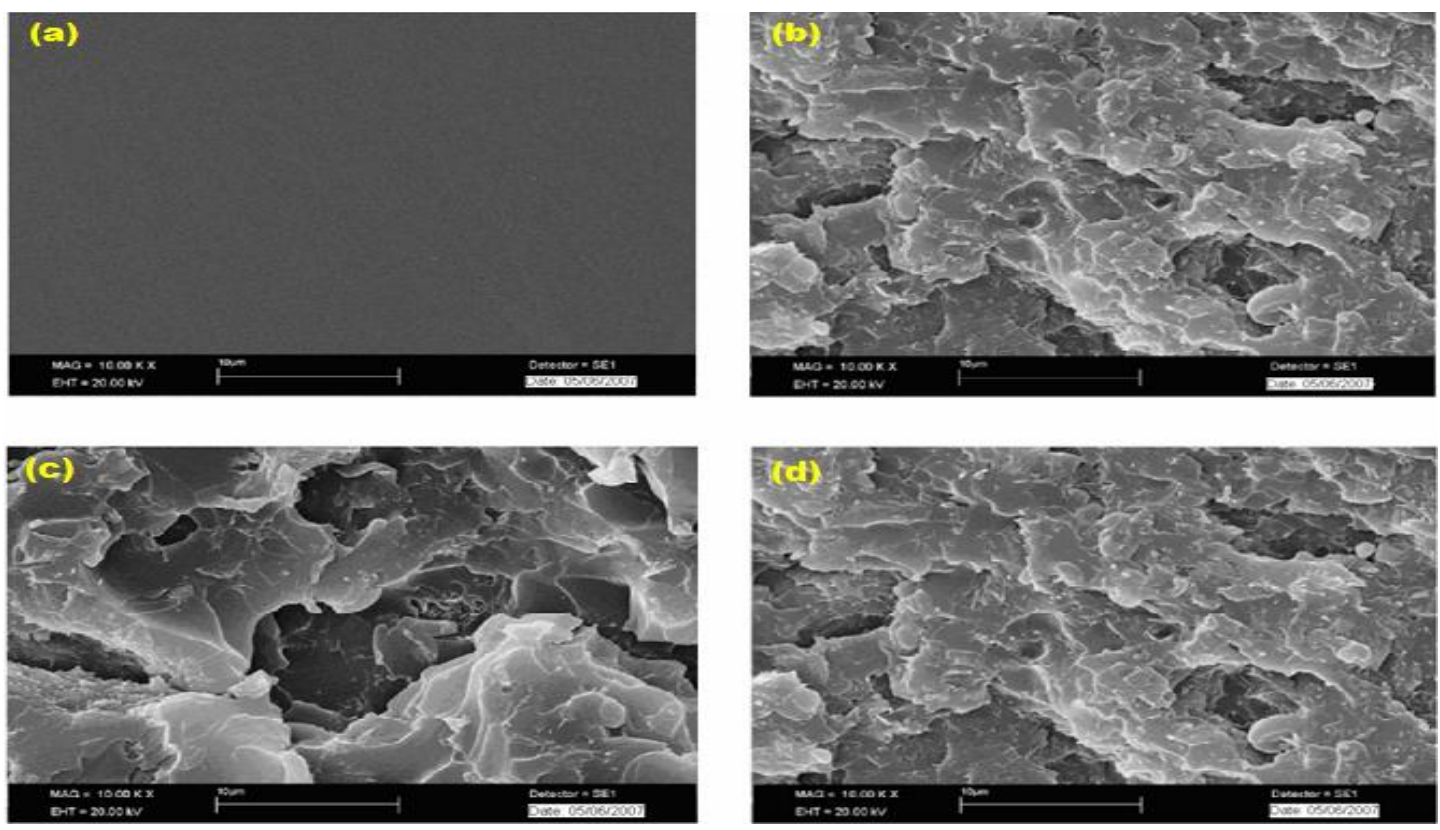

Figure 8. SEM photograph of (a) neat epoxy (b) 2 wt. \% CB (c) 3 wt. \% CB (d) 4 wt. \% CB

\section{Conclusions}

In this paper, the neat epoxy is successfully fabricated with up to 4 wt. \% of CB filler. The tensile strength of the neat epoxy increased from $39 \pm 2.2 \mathrm{MPa}$ to $58 \pm 2.6 \mathrm{MPa}$ with $4 \mathrm{wt}$. \% of CB loading. The strength increases steadily up to 4 wt. $\%$ of CB loading after that it decreases. The neat epoxy resin has the maximum impact strength $1.5 \mathrm{~kJ} / \mathrm{m}^{2}$ and composite at $4 \mathrm{wt} \%$ composite has the maximum impact strength of $2.7 \mathrm{~kJ} / \mathrm{m}^{2}$. The neat epoxy has a Tg of $68{ }^{\circ} \mathrm{C}$, the addition of 4 wt. \% CB into the epoxy resin increased $\mathrm{Tg}$ to $90{ }^{\circ} \mathrm{C}$. The initial decomposition temperature of the neat epoxy increased from $302{ }^{\circ} \mathrm{C}$ to $310{ }^{\circ} \mathrm{C}$ with 4 wt. \% CB loading. Neat epoxy has char formation of $4.94 \%$ and, char formation is $11.68 \%$ for composites with 4 wt. \% CB content.

\section{Nomenclature}

CB Carbon black

TGA Thermal graphic analysis

DSC Differential scanning calorimeter

Tg Glass transition

wt. \% Weight percentage

SEM Scanning electron microscope

EG Exfoliated graphite

UTM Universal testing machine

H.S.M High-intensity mechanical stirrer

DGEBA Diglycidyl ether of bisphenol A

\section{References}

Bai, J.B. and Allaoui, A., 2003. Effect of the length and the aggregate size of MWNTs on the improvement efficiency of the mechanical and electrical properties of nanocomposites-experimental investigation. Composites Part A: Applied Science and Manufacturing, Vol. 34, No. 8, pp. 689-694.

Etika, K.C., Liu, L., Hess, L.A. and Grunlan, J.C., 2009. The influence of synergistic stabilization of carbon black and clay on the electrical and mechanical properties of epoxy composites. Carbon, Vol. 47, No. 13, pp. 3128-3136.

El-Tantawy, F., Kamada, K. and Ohnabe, H., 2002. In situ network structure, electrical and thermal properties of conductive epoxy resin-carbon black composites for electrical heater applications. Materials Letters, Vol. 56, No. 1-2, pp. 112-126.

Gojny, F.H. and Schulte, K., 2004. Functionalisation effect on the thermo-mechanical behaviour of multi-wall carbon nanotube/epoxy-composites. Composites Science and Technology, Vol. 64, No. 15, pp. 2303-2308. 
Guadagno, L., Vertuccio, L., Sorrentino, A., Raimondo, M., Naddeo, C., Vittoria, V., Iannuzzo, G., Calvi, E. and Russo, S., 2009. Mechanical and barrier properties of epoxy resin filled with multi-walled carbon nanotubes. Carbon, Vol. 47, No. 10, pp. 24192430.

https://en.wikipedia.org/wiki/Carbon_black.

Imoisili, P.E., Ukoba, K.O., Adejugbe,I.T., Adgidzi, D. and Olusunle, S.O.O., 2013. Mechanical properties of rice husk/carbon black hybrid natural rubber composite. Chemistry and Materials Research, Vol. 3, No. 8, pp. 12-16.

Inam, F., Vo, T., Jones, J.P. and Lee, X., 2013. Effect of carbon nanotube lengths on the mechanical properties of epoxy resin: An experimental study. Journal of Composite Materials, Vol. 47, No. 19, pp. 2321-2330.

Jakab, E. and Omastová, M., 2005. Thermal decomposition of polyolefin/carbon black composites. Journal of Analytical and Applied Pyrolysis, Vol. 74, No.1-2, pp. 204-214.

Khalil, H.A., Firoozian, P., Bakare, I.O., Akil, H.M. and Noor, A.M., 2010. Exploring biomass based carbon black as filler in epoxy composites: Flexural and thermal properties. Materials \& Design, Vol. 31, No. 7, pp. 3419-3425.

Kuzhir, P., Paddubskaya, A., Plyushch, A., Volynets, N., Maksimenko, S., Macutkevic, J., Kranauskaite, I., Banys, J., Ivanov, E., Kotsilkova, R. and Celzard, A., 2013. Epoxy composites filled with high surface area-carbon fillers: Optimization of electromagnetic shielding, electrical, mechanical, and thermal properties. Journal of Applied Physics, Vol. 114, No. 16, pp. 164304.

Leemsuthep A., Mohd Nayan, N.A., Zakaria, Z. and Uy Lan, D.N., 2017. Effect of sodium bicarbonate in fabrication of carbon black - filled epoxy porous for conductive application. Macromolecular Symposia, Vol. 371, No. 1, pp. 44-49.

Li, H.Y., Chen, H.Z., Xu, W.J., Yuan, F., Wang, J.R. and Wang, M., 2005. Polymer-encapsulated hydrophilic carbon black nanoparticles free from aggregation. Colloids and Surfaces A: Physicochemical and Engineering Aspects, Vol. 254, No. 1-3, pp. 173-178.

Nayak, R.R., Lee, K.Y., Shanmugharaj, A.M. and Ryu, S.H., 2007. Synthesis and characterization of styrene grafted carbon nanotube and its polystyrene nanocomposite. European Polymer Journal, Vol. 43, No.12, pp. 4916-4923.

Okieimen F.E. and Iman J., 2003. The characterization of agricultural waste product as filler in NR formulations. Nigerian Journal of Polymer Science and Technology, Vol. 3, No. 1, pp. 178-240.

Okieimen, F.E. and Imanah, J.E., 2003. Characterization of agricultural waste products as fillers in natural rubber formulation. Nigerian Journal of Polymer Science and Technology, Vol. 3, No. 1, pp. 210-216.

Phua, J.L., Teh, P.L., Ghani, S.A. and Yeoh, C.K., 2017. Influence of thermoplastic spacer on the mechanical, electrical, and thermal properties of carbon black filled epoxy adhesives. Polymers for Advanced Technologies, Vol. 28, No. 3, pp. 345-352.

Rahmani, H., Najafi, S.H.M. and Ashori, A., 2014. Mechanical performance of epoxy/carbon fiber laminated composites. Journal of Reinforced Plastics and Composites, Vol. 33, No. 8, pp. 733-740.

Remiro, P.M., Cortazar, M., Calahorra, E. and Calafel, M.M., 2002. The effect of crosslinking and miscibility on the thermal degradation of an uncured and an amine-cured epoxy resin blended with poly ( $\varepsilon$-caprolactone). Polymer Degradation and Stability, Vol. 78, No.1, pp. 83-93.

Rosszainily, I.R.A., Salim, M.A., Mansor, M.R., Akop, M.Z., Putra, A., Musthafah, M.T., Hassan, M.Z., Rahman, M.N. and Sudin, M.N., 2016. Effect of carbon black fillers on tensile stress of unvulcanized natural rubber compound. Journal of Mechanical Engineering and Sciences, Vol. 10, No. 2, pp. 2043-2052.

Sun, Y., Zhang, Z., Moon, K.S. and Wong, C.P., 2004. Glass transition and relaxation behavior of epoxy nanocomposites. Journal of Polymer Science Part B: Polymer Physics, Vol. 42, No. 21, pp.3849-3858.

Wen, Y., Song, J., Chen, J., Sun, Y. and Yang, W., 2017. Synergistic conductivity and electromagnetic interference shielding effectiveness of epoxy/carbon fiber and epoxy/carbon black composites via mixing with bamboo charcoal. BioResources, Vol. 12, No. 1, pp. 1288-1299.

Yang, K., Gu, M., Guo, Y., Pan, X. and Mu, G., 2009. Effects of carbon nanotube functionalization on the mechanical and thermal properties of epoxy composites. Carbon, Vol. 47, No. 7, pp. 1723-1737.

Yue, J., Xu, Y. and Bao, J., 2017. Epoxy-carbon black composite foams with tunable electrical conductivity and mechanical properties: Foaming improves the conductivity. Journal of Applied Polymer Science, Vol. 134, No. 33, pp. 45071.

Yuen, S.M., Ma, C.C.M., Wu, H.H., Kuan, H.C., Chen, W.J., Liao, S.H., Hsu, C.W. and Wu, H.L., 2007. Preparation and thermal, electrical, and morphological properties of multiwalled carbon nanotubeand epoxy composites. Journal of Applied Polymer Science, Vol. 103, No. 2, pp. 1272-1278.

Zhang, W., Zhang, X., Liang, M. and Lu, C., 2008. Mechanochemical preparation of surface-acetylated cellulose powder to enhance mechanical properties of cellulose-filler-reinforced NR vulcanizates. Composites Science and Technology, Vol. 68, No.12, pp. 2479-2484.

Zhou, T., Wang, X., Liu, X. and Xiong, D., 2010. Improved thermal conductivity of epoxy composites using a hybrid multi-walled carbon nanotube/micro-SiC filler. Carbon, Vol. 48, No. 4, pp. 1171-1176.

\section{Biographical notes}

Tanusree Bera is a Research Scholar in the Department of Mechanical Engineering, National Institute of Technology, Rourkela, India. 
S.K. Acharya is a Professor in the Department of Mechanical Engineering, National Institute of Technology Rourkela, India. He has more than 24years of experience in teaching and research. His current area of research includes Tribology, Composite materials and Nano Technology. He has published more than thirty papers in referred national and international journals. He has also presented more than seventy five research articles in national and international conferences.

Punyapriya Mishra is an Associate Professor in the Department of Mechanical Engineering, Veer Surendra Sai University of Technology, Burla, India

Received July 2018

Accepted July 2018

Final acceptance in revised form August 2018 